\title{
Results of a Conservative Management of Minimally Displaced Lateral Condyle of Humerus Fracture in Children
}

\author{
Shrestha DK ${ }^{1}$, Bastola $\mathrm{P}^{2}$, Dhungel $\mathrm{B}^{3}$, Lakhanpal VP ${ }^{4}$
}

\begin{abstract}
Background: Fracture of lateral condyle humerus in pediatric population is second most common elbow injury. There is controversy regarding treatment of minimally displaced (less than $2 \mathrm{~mm}$ ) fracture. If this group can be taken care with non operative treatment it will be an easier and lot cheaper option especially for rural parts of west Nepal. Aim: To see the viability of treatment of minimally displaced lateral condyle humerus fracture with non operative treatment and look for short and immediate results. Methodology: This was a prospective observational, hospital based study carried out in Nepalgunj Medical College teaching Hospital from Jan. 2013 - Jan. 2014. In children between 2.5 - 13 years, with minimally displaced fracture of lateral condyle humerus were radiologically followed up for 12 weeks. All patients underwent long arm cast and serial radiographs in follow ups. At 12 weeks; range of motion, tenderness and carrying angle were looked for. Results: There were 12 patients in the study with average age of 6.95 years, range (SD 2.92). There were no displacements in follow ups. At 6 weeks all had full range of motion and at 12 weeks all had full range of motion without tenderness. Three kids had approximately 5 degrees of carrying angle change on other side to varus. Conclusion: Non operative treatment with 4 weeks of long arm cast in supination is a good alternative option for minimally displaced lateral condyle fracture humerus. A good follow up of the treated patients is an integral part of management along with radiological evidence. Parents need to be warned about bump in the lateral side during healing.
\end{abstract}

Key words: Conservative management, lateral condyle of humerus, minimal displacement

\section{INTRODUCTION:}

Fractures of the lateral condyle of humerus represent $12 \%$ $20 \%$ of all fractures of the distal end of the humerus in children. ${ }^{1.3}$ They have been shown to be caused primarily by forced varus angulation with the elbow extended and supinated. With an estimated annual incidence of 1.6 per 10,000 in the United States, ${ }^{3}$ lateral humeral condylar fractures is the second most common pediatric elbow fracture after supracondylar humerus fracture.

It typically occurs in children aged approximately 6 years..$^{3-4}$ Controversy exists regarding the management of nondisplaced and minimally displaced (less than $2 \mathrm{~mm}$ ) fractures. These fractures account for $33 \%$ to $69 \%$ of lateral humeral condylar fractures. ${ }^{5-7}$

1. Dr. Dinesh Kumar Shrestha

2. Dr. Pradeep Bastola

3. Dr. Binayak Dhungel

4. Prof. V. P. Lakhanpal

Address of correspondence:

Dr. Dinesh Kumar Shrestha

Department of Orthopedics

Nepalgunj Medical College Teaching Hospital

Kohalpur, Banke, Nepal

E-mail: dr_dineshstha@yahoo.com
Minimally displaced fractures are amenable to nonsurgical management. This study primarily aimed to see the immediate and short term results in non surgical management of lateral condyle humerus fracture in children.

\section{MATERIALS AND METHODS}

The present study was a retrospective observational study conducted in Nepalgunj Medical College Teaching Hospital (NGMCTH), Kohalpur from Jan. 2013 - Jan. 2014 in the Department of Orthopedics. All pediatric patients $(2.5-13$ years of age) attending to the orthopedic outpatient department (OPD) or emergency (ER) department with suspected elbow injury were included. The study strictly adhered to the tenets of declaration of Helsinki. An ethical informed consent too was taken from the patient party and NGMCTH to carry the study. Data on our interest were taken from record section of included patients.

After primary management in the ER examination of the patients was carried out by 2 orthopedic surgeons. Three view $x$-rays of elbow were done including antero - posterior, medial/internal oblique (Figure 1,2) and lateral. Patients with type I lateral condyle fracture ${ }^{1}$, displaced less than $2 \mathrm{~mm}$ in all three views were included in the study. Patients losing in follow up, over 13 years of age or less than 2.5 years of age, not responding to the telephone calls and X-ray films not showing fractures in all three films were excluded from the study. 


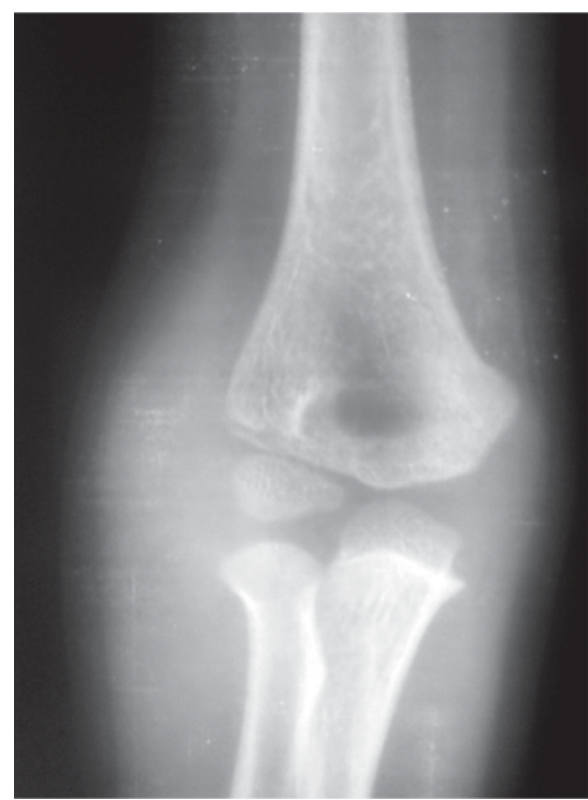

Figure 1: Showing antero - posterior view of a $X$ - ray film

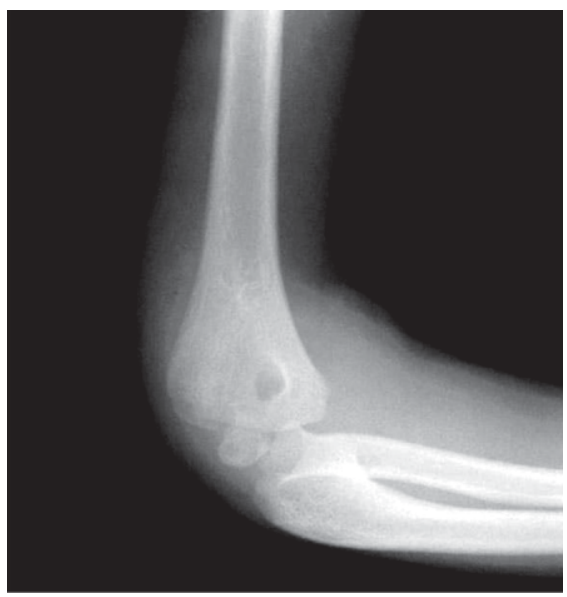

Figure 2: Showing internal oblique radiographic view

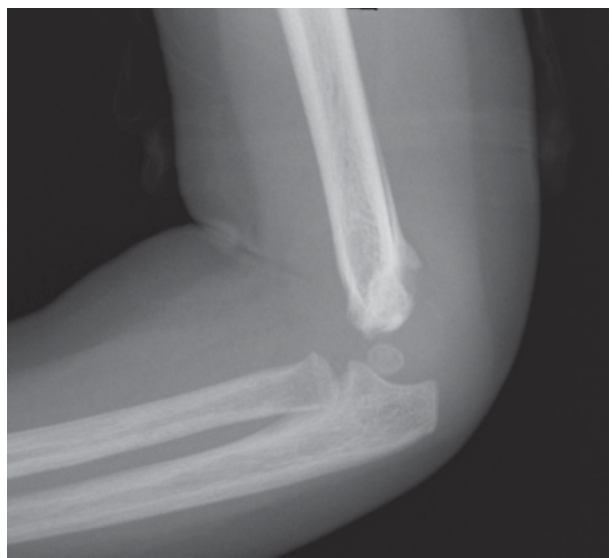

Figure 3: Showing lateral radiographic view of the study subject at 4 weeks follow up

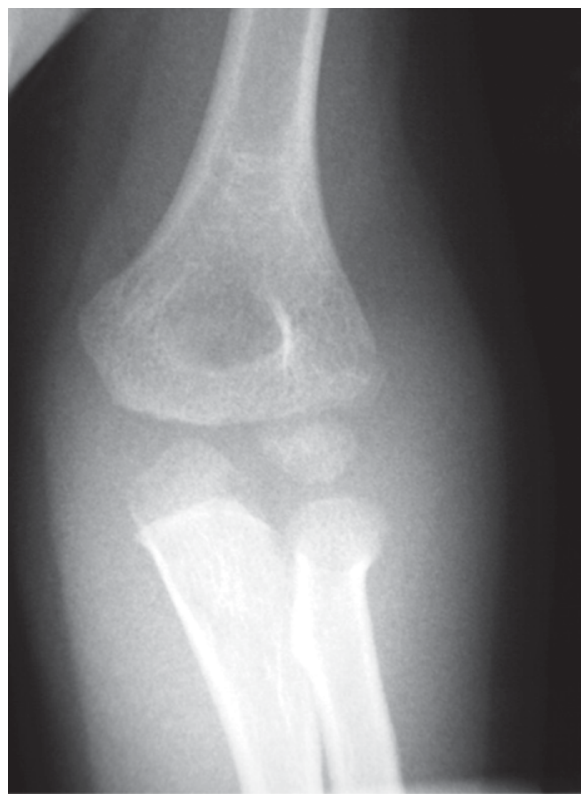

Figure 4: Showing antero posterior radiographic view of the study subject at 4 weeks follow up

Patients were placed in a long arm cast and admitted overnight to observe any swelling and were discharged the next day and followed up in 7 days. In a week follow up, same $x$ rays were repeated to note any change in alignment or displacement. Similar follow ups were done in 2 weeks, 4 weeks. At 4 weeks cast was removed and range of motion started. Patient parents were called by direct phone call by the surgeon to examine the patient at 6 weeks and 12 weeks. In the last two visits range of motion, carrying angle, deformity were checked.

All the relevant information was entered in to Microsoft word, Statistical Package for Social Services (SPSS) version 19, Microsoft Excel and analyzed.

\section{RESULTS}

A total of 12 patients enrolled in the study. Gender wise male is to female ratio was 1:1. Average age of study subjects was 6.95 years, range $2.5-13$ years (SD 2.92). Fall from height was the commonest cause of fracture followed by road traffic accidents (RTAs). At 6 weeks all patients had full range of motion of the elbow. At 12 weeks range of motion was full in all. 9 (75\%) kids had less than 3 degrees difference in carrying angle. Three $(25 \%)$ kids had 5 degree change in carrying angle to varus. Three (25\%) kids had bump in the lateral side (Table 1 ). Callus extending to lateral ridge was noticed in all the study subjects. None of the study subjects had malunion in X-rays (Figure 3 ).

\section{DISCUSSION}

Lateral humeral condyle fracture in children is difficult to diagnose. Most of the poor results reported in the literature were due to defective initial management. ${ }^{8,9}$ The present study confirmed the good clinical and radiological results obtained with non surgical treatment. 


\begin{tabular}{|c|c|c|c|c|c|c|c|c|c|}
\hline Case & Gender & $\begin{array}{c}\text { Age } \\
\text { (years) }\end{array}$ & $\begin{array}{c}\text { Mode } \\
\text { of injury }\end{array}$ & $\begin{array}{c}\text { Displacement } \\
\text { (Radiographs) }\end{array}$ & $\begin{array}{c}\text { Fracture } \\
\text { Type (Milch)* }\end{array}$ & Treatment & $\begin{array}{c}\text { Follow } \\
\text { (weeks) }\end{array}$ & $\begin{array}{c}\text { Amount of } \\
\text { angulation and } \\
\text { complaints }\end{array}$ & Results \\
\hline 1 & M & 6 & RTA & $2 \mathrm{~mm}$ & I & Non Surgical & 12 & Bump** & Excellent \\
\hline 2 & M & 8 & Fall & $2 \mathrm{~mm}$ & I & Non Surgical & 12 & None & Excellent \\
\hline 3 & F & 2.5 & Fall & $1 \mathrm{~mm}$ & I & Non Surgical & 12 & None & Excellent \\
\hline 4 & F & 3 & RTA & $2 \mathrm{~mm}$ & I & Non Surgical & 12 & Varus of 5 degrees & Good \\
\hline 5 & M & 13 & Fall & $2 \mathrm{~mm}$ & I & Non Surgical & 12 & Bump** & Excellent \\
\hline 6 & F & 8 & Fall & $2 \mathrm{~mm}$ & I & Non Surgical & 12 & None & Excellent \\
\hline 7 & M & 4 & Fall & $2 \mathrm{~mm}$ & I & Non Surgical & 12 & None & Excellent \\
\hline 8 & F & 5 & Fall & $1 \mathrm{~mm}$ & I & Non Surgical & 12 & Bump** & Excellent \\
\hline 9 & M & 6 & Fall & $2 \mathrm{~mm}$ & I & Non Surgical & 12 & Varus of 5 degrees & Good \\
\hline 10 & M & 6 & Fall & $2 \mathrm{~mm}$ & I & Non Surgical & 12 & None & Excellent \\
\hline 11 & F & 3 & Fall & $1 \mathrm{~mm}$ & I & Non Surgical & 12 & Varus of 5 degrees & Good \\
\hline 12 & F & 5 & RTA & $2 \mathrm{~mm}$ & I & Non Surgical & 12 & None & Excellent \\
\hline
\end{tabular}

*Following Milch grading of lateral humeral condyle fractures

**Bump in the lateral side of the elbow

Table I: Showing various findings from the study

Gender wise there was no difference in number of boys and girls in the present study, which differed from a study which had more number of girls with lateral condylar fracture of humerus. ${ }^{10}$

Commonest age group of presentation of lateral humeral condyle fracture is 6 yrs. ${ }^{4}$ In the present study also; the average age of presentation of the children was 6.95 years.

Antero-posterior (AP), lateral, and internal oblique radiographs of the affected elbow should be obtained in patients with suspected fracture of the lateral humeral condyle. ${ }^{11}$ Anteroposterior radiographic views demonstrate a small metaphyseal flake with minimal displacement; an internal oblique view is obtained to better evaluate the fracture pattern and the amount of displacement. ${ }^{12}$ In fractures with minimal displacement (less than $2 \mathrm{~mm}$ ), the fracture may be appreciated only on the internal oblique view. ${ }^{12}$ Song et al, ${ }^{13}$ (2007) found that the internal oblique view more accurately demonstrated the degree of displacement than did the anteroposterior view. In this study also AP, lateral and internal oblique radiographs were taken, which confirmed the fractures and displacements.

In the present study 9 (75\%) of the study subjects had history of fall injury and $25 \%$ remainder of study subjects had history of RTAs. This finding of the study again differed with the existing literature. As the etiology of lateral humeral condyle fracture has been described by two theories, which are the pull-off theory, in which avulsion of the lateral condyle occurs at the origin of the extensor/supinator musculature and is the commonest cause. The second is the push-off theory, in which a fall onto the extended hand leads to impaction of the radial head into the lateral condyle, causing the fracture. ${ }^{14}$

Milch $(1964)^{1,15}$ described two lateral condylar fracture patterns. Type I fractures are characterized by a fracture line that courses lateral to the trochlea and into the capitulo trochlear groove, resulting in a Salter- Harris type IV fracture. The elbow remains stable because the trochlea is intact. Milch type II fracture is characterized by a fracture line that extends into the apex of the trochlea, resulting in a Salter-Harris type II fracture. This study had all the study subjects with type I lateral humeral condyle fracture according to Milch's classification.

Controversy exists regarding the management of nondisplaced and minimally displaced fractures. Flynn et al, (1975), ${ }^{2}$ noted that minimally displaced fractures healed quickly with abundant callus formation. Many authors have suggested that all lateral humeral condylar fractures should be managed surgically because of the risk of displacement and the high rate of nonunion. ${ }^{16,17}$ Flynn, $(1989)^{18}$ reviewed 23 cases of nonunion following lateral condylar fracture with initial displacement measuring less than $2 \mathrm{~mm}$. In 12 cases, late fracture displacement resulted in nonunion. Launay et al, (2004), ${ }^{19}$ retrospectively reviewed the outcome of 30 non displaced lateral condylar fractures, of which 17 were initially managed none surgically. Four patients in the nonsurgical group went on to substantial displacement and required surgical treatment. Two patients went on to nonunion, and two went on to 
malunion. Of the 13 patients who were initially treated surgically, 2 went on to malunion. There were no cases of nonunion in this group. The authors recommended nonsurgical management only when follow up could be assured. In this study till the last follow up (12 weeks) none of the study subjects had malunion or nonunion, however three study participants had developed bump which was noticed in follow up at 4 weeks time. Callus formation in lateral ridge of distal humerus was present in all the participants.

Pirker et al, (2005), ${ }^{7}$ managed 51 lateral humeral condyle fractures (displacement less than $2 \mathrm{~mm}$ ) with above-elbow plaster splints for 2 to 7 days. Five patients had subsequent displacement, all within the first week. Displacement was easily detected on follow-up radiographs, with sufficient time for surgical management. Thus, these authors argued that fractures with displacement less than $2 \mathrm{~mm}$ can be managed with immobilization and close radiographic follow-up. Similarly, Bast et al,(1998), ${ }^{20}$ found that of 95 patients with less than $2 \mathrm{~mm}$ fracture displacement who were treated with cast immobilization, only 2 displaced during immobilization and went on to require surgical fixation. This again proves to the point about controversy regarding the management of lateral humeral condyle fractures.

\section{Limitations of the study}

The small sample size of the study is a major limitation of the study. Use of Magnetic Resonance Imaging (MRI) would have given exact and precise measurement of displacement and not be representative of all the participants of similar age. Radiographic documentation of the contralateral normal hand would have been good as ossification do occur in the study sample age group.

\section{Conclusions/Recommendations}

This study concluded that, minimally displaced fractures of lateral humeral condyle (less than $2 \mathrm{~mm}$ displacement in all views of radiographs) can be treated with casting for 4 weeks with strict monitoring and regular follow ups. A bump in the lateral area of the elbow is the commonest complication.

\section{Acknowledgments}

We would like to sincerely thank the participants for being part of the study.

Finally, we would like to acknowledge Dr. Pradeep Bastola, Mr. Garbu Chaudhary, Mr. Khemu Singh from Department of Radiology, and the entire team of Department of Emergency NGMCTH.

\section{REFERENCES:}

1. Milch H: Fractures and fracture dislocations of the humeral condyles. J Trauma 1964;4:592-607.

2. Flynn JC, Richards JF, Saltzman RI. Prevention and treatment of non-union of slightly displaced fractures of the lateral humeral condyle in children: An end-result study. J Bone Joint Surg Am 1975;57(8):1087-1092.

3. Landin LA: Fracture patterns in children. Analysis of 8,682 fractures with special reference to incidence, etiology and secular changes in a Swedish urban population 1950-1979. Acta Orthop Scand Suppl 1983;202:1-109.

4. Stimson L: A Practical Treatise on Fractures and Dislocations. Philadelphia, PA, Lea Brothers \& Co, 1900.

5. Rutherford A: Fractures of the lateral humeral condyle in children. J Bone Joint Surg Am 1985;67(6):851-856.

6. Foster DE, Sullivan JA, Gross RH. Lateral humeral condylar fractures in children. J Pediatr Orthop 1985;5(1):16-22.

7. Pirker ME, Weinberg AM, Höllwarth ME, Haberlik A. Subsequent displacement of initially nondisplaced and minimally displaced fractures of the lateral humeral condyle in children. J Trauma 2005;58(6):1202-1207.

8. D.E. Foster, J.A. Sullivan, R.H. Gros. Lateral humeral condylar fractures in children. J Pediatr Orthop, 1985;5:16-22

9. J.C. Flynn. Nonunion of slightly displaced fractures of the lateral humeral condyle in children: an update. J Pediatr Orthop, 1989;9: 691-696

10. Marcheix PS, V. Vacquerie, Longis B, Peyrou P, L. Fourcade, D. Moulies. Distal humerus lateral condyle fracture in children: When is the conservative treatment a valid option? J Orthopaedic Surgery and Traumatology Review 2011;97(3):290-94

11. Gaston MS, Irwin GJ, Huntley JS. Lateral condyle fracture of a child's humerus: the radiographic features may be subtle. Scott Med J. Aug 2012;57(3):182

12. Milch H: Fractures of the external humeral condyle. J Am Med Assoc 1956;160(8):641-646.

13. Flynn JC: Nonunion of slightly displaced fractures of the lateral humeral condyle in children: An update. J Pediatr Orthop1989;9(6):691-696.

14. Janos PE, Harris G. Lateral Humeral Condyle Fracture. (cited April 7, 2015 ) ava ilable on I ine: http://emedicine.medscape.com/article/1231199. overview\#a0102

15. McLearie M, Merson RD. Injuries to the lateral condyle epiphysis of the humerus in children. J Bone Joint Surg Br 1954;36(1):84-89.

16. Song KS, Kang CH, Min BW, Bae KC, Cho CH. Internal oblique radiographs for diagnosis of nondisplaced or minimally displaced lateral condylar fractures of the humerus in children. Bone Joint Surg Am 2007;89(1):58-63.

17. Jakob R, Fowles JV, Rang M, Kassab MT: Observations concerning fractures of the lateral humeral condyle in children. J Bone Joint Surg Br 1975;57(4):430-436.

18. Conner AN, Smith MG: Displaced fractures of the lateral humeral condyle in children. J Bone Joint Surg Br 1970; 52(3):460-464.

19. Launay F, Leet Al, Jacopin S, Jouve JL, Bollini G, Sponseller PD. Lateral humeral condyle fractures in children: A comparison of two approaches to treatment. J Pediatr Orthop 2004;24(4):385391.

20. Bast SC, Hoffer MM, Aval S. Non operative treatment for minimally and nondisplaced lateral humeral condyle fractures in children. J Pediatr Orthop 1998;18(4):448-450. 